for work-relatedness, and 4) coding work-related cases. Workrelated cases were classified as workers, bystanders, commuters or students. Work-related injury frequencies and rates per 100000 workers for the most recent 20 year period were calculated by age, sex, employment status, occupation and industry.

Results Of 17658 injury fatalities reviewed for the period 1995-2014, 3766 (23\%) were work-related, of which 1762 were workers. This corresponds to an overall rate of fatal injury of 4.7 (95\% CI 4.5, 5.0) per 100000 workers. Rates of fatal injury were highest for older workers aged 70-84 years $(18.1,95 \%$ CI $14.8,21.8)$ and males $(8.1,95 \%$ CI 7.7 , 8.5). The two industry groups with the highest burden of fatal injury were the Agricultural, Forestry and Fisheries and Transport, Postal and Warehouse.

Conclusions This research demonstrates an innovative use of coronial data, and provides a rare example of the establishment of a continuous and comprehensive long-term coronial dataset. It will be used to generate knowledge for informing workplace preventive strategies in NZ.

\section{A.4 HAZARDS AND INJURIES ASSOCIATED AMONG SMALL SCALE GOLD MINERS IN THE PHILIPPINES}

Jinky Leilanie Lu*. National Institutes of Health, University Of The Philippines Manila, Manila, Philippines, National Telehealth Center, NIH, UP Manila, Manila, Philippines

\subsection{6/OEM-2019-EPI.166}

Worldwide, small-scale mining (SSM) provides employment to about 13 million people and affects the livelihood of 80 100 million. This study investigated the ergonomic and safety hazards of small scale miners in one of the largest small scale mining area in the Philippines which is the area of Itogon, Benguet. There were 93 small scale miners who were included in the study as they complied with the inclusion criteria. The methods consisted of survey questionnaires, health physical examination guide, individual interviews, and work process observation tool. The results showed that the smallscale miners worked for an average of 10.7 years, and a maximum work year of 40 . The most widely employed mining technique was the dog-hole mining consisting of several sub-processes -tunneling, ball milling and gravity concentration, cyanide leaching, and smelting. The ergonomic and safety hazards identified were noise exposure from the dynamite blast, temperature extremes, and exposure to dust from dynamite blasting. The miners experienced prolonged crouching and bending, prolonged handling of tools, and carrying heavy sacks filled with mineral ores. In the ball milling and gravity concentration process, machine-related accidents were noted such as cuts from the crusher. In the cyanide leaching which uses massive amounts of cyanide, the most prevalent hazards were heat, dust, and chemicals such as cyanide fumes. In the smelting process, smoke from burning ore and coal as well as exposure to borax and nitric acid fumes. Burn injuries were reported among miners. A third (31.2\%) of miners have experienced accidents. The most common injury was laceration at $47.8 \%$, followed by methane inhalation, fracture of hand digits, and contusion at $17.4 \%$. The most prevalent health symptom reported by the miners was muscle pain. It is suggested that intervention programs for ergonomics and safety measures be implemented by the local government.

\section{Psychosocial Factors}

\section{B.1 MODELLING MORTALITY BY SUICIDE AMONG WOMEN AT WORK IN THE SWISS NATIONAL COHORT}

${ }^{1,2}$ Pascal Wild*, ${ }^{2}$ Nicolas Bovio, ${ }^{2}$ Irina Guseva Canu. 'INRS, Vandoeuvre Les Nancy Cedex, France; ${ }^{2}$ Institute for Work and Health (IST), Lausanne, Switzerland

\subsection{6/OEM-2019-EPI.167}

Context The aim of this study was to describe the factors associated with mortality by suicide among women at work with a particular focus on work-related factors.

Population and methods The study population was based on the data of the Swiss National Cohort (SNC) consisting in all Swiss residents recorded in the 1990 and/or the 2000 compulsory national censuses linked to emigration and mortality registers. Within the SNC we selected all working women aged between 18 and 65 at the official census dates.

Following work-related variables were available in both censuses: Socio-economic status, weekly hours of work, the sector of activity according to the Swiss NOGA scheme and the job title coded according to ISCO. The date of beginning of follow-up was the date of the relevant census. The date of end of follow-up was the earliest of the 65th anniversary, dec 31 st 2014 (the end of mortality follow-up), the date of loss of follow-up or dec 4th 2010 if no declared work in the 2000 census. The risk of suicide was modelled using negative binomial regression incorporating the number of person-years as offset.

Results The cohort comprised 1,843,619 women and 2524 deaths by suicide corresponding to 24.9 million personyears. The most significant non-occupational predictors of suicide were age, civil status, period, nationality and geographical regions. Part-time work and long working hours were associated with increased suicide rates. Health and social activities had the highest suicide risks and education the lowest. Overall the job title according to ISCO-1d was not significant. However the rank of suicide risk among women followed approximately the skill levels associated with these codes. Of interest is however the high RR among professionals.

Conclusion After accounting for the main non-occupational factors, the suicide risk varied significantly with some workrelated factors that were specific for women.

\section{O7B.2 PILOT PROJECT FOR IDENTIFYING PSYCHOSOCIAL RISK FACTORS AMONG SENIOR PHYSICIANS IN THE PEDIATRIC MEDICAL CENTER OF A UNIVERSITY HOSPITAL CENTER}

${ }^{1,2}$ Marie-Agnès Denis*, ${ }^{2}$ Fabienne Dumetier, ${ }^{3}$ Ghislaine Poyard-Berger, ${ }^{4}$ Marie-
Michèle Mantha-Belisle, ${ }^{4}$ Michel Vézina. ${ }^{1}$ Univ Lyon, Université Claude Bernard Lyon1,
Ifsttar, Umrestte, Umr T_9405, F- 69373, Lyon; ${ }^{2}$ Service de médecine et santé au travail,
Hospices Civils de Lyon - 59 Bd Pinel, F- 69677 Bron cedex; ${ }^{3}$ Direction du personnel et des
affaires sociales, Hospices Civils de Lyon -162 av Lacassagne, F-69424 Lyon cedex 03;
${ }^{4}$ INSPQ, Direction des risques biologiques et de la santé au travail, Santé au travail, 90
Boulevard Crémazie E, Montréal, QC H2P 1E2, Canada

\subsection{6/OEM-2019-EPI.168}

Context After several warning signals coming from senior physicians working in a Department of pediatrics at a large university hospital, the Department of occupational health 